\title{
Positive celiac disease serology and reduced bone mineral density in adult women
}

\author{
Donald R Duerksen MD, William D Leslie MD MSc
}

DR Duerksen, WD Leslie. Positive celiac disease serology and reduced bone mineral density in adult women. Can J Gastroenterol 2010;24(2):103-107.

BACKGROUND: Low bone density and osteoporosis have been demonstrated in celiac disease populations in Europe, South America and the United States. Serological testing with tissue transglutaminase (TTG) and immunoglobulin A endomysial (EMA) antibodies is highly specific for celiac disease, while antigliadin antibody (AGA) testing is less specific.

OBJECTIVE: To evaluate the association of celiac serology with reduced bone density in adult women.

METHODS: A clinical database containing all bone density testing data in the province of Manitoba was linked to a database containing all celiac serology data for the province. The study cohort consisted of 376 women older than 20 years of age with bone density measurements preceding initial celiac serology by six months or less. Bone density was assessed in relation to TTG/EMA and AGA seropositivity, and compared with seronegative controls in age-, height- and weightadjusted models.

RESULTS: There was significantly lower bone density in TTG/EMA seropositive women than with seronegative controls for all sites tested (lumbar spine, total hip, trochanter, femoral neck; all $\mathrm{P}<0.05$ ). TTG/ EMA seropositive women also had a significantly higher prevalence of osteoporosis $(67.7 \%$ versus $44.8 \% ; \mathrm{P}<0.05)$. There was lower bone density at the three hip sites (all $\mathrm{P}<0.05)$ in AGA seropositive women, but after excluding TTG/EMA seropositive women, isolated AGA seropositivity showed no significant association with any bone density measurements.

CONCLUSION: TTG/EMA seropositivity was associated with lower bone density and a higher prevalence of osteoporosis compared with seronegative controls.

Key Words: Bone density; Celiac disease; Celiac serology; Osteoporosis

\section{Une sérologie positive de la maladie coliaque et une diminution de la densité minérale osseuse chez des femmes adultes}

\begin{abstract}
HISTORIQUE : Une faible densité osseuse et l'ostéoporose sont démontrées dans les populations atteintes d'une maladie cœeliaque d'Europe, d'Amérique du Sud et des États-Unis. Les tests sérologiques au moyen des anticorps de la transglutaminase tissulaire (TTG) et de l'immunoglobuline A endomysium (EMA) sont très spécifiques à la maladie cœliaque, tandis que les tests aux anticorps anti-gliadine (AGA) le sont moins.

OBJECTIF : Évaluer l'association entre la sérologie cœliaque et la diminution de la densité osseuse chez les femmes adultes.

MÉTHODOLOGIE : Les auteurs ont lié une base de données clinique contenant toutes les données tirées des tests de densité osseuse de la province du Manitoba à une base de données contenant toutes les données de sérologie cœliaque de cette province. La cohorte à l'étude se composait de 376 femmes de plus de 20 ans dont les mesures de densité osseuse précédaient la première sérologie cœliaque d'un maximum de six mois. Ils ont évalué la densité osseuse par rapport à la séropositivité à la TTG/EMA et à l'AGA et l'ont comparée aux sujets témoins séronégatifs de modèles rajustés selon l'âge, la taille et le poids.

RÉSULTATS : La densité osseuse était considérablement plus faible chez les femmes séropositives à la TTG/EMA que chez les sujets témoins séronégatifs dans tous les foyers évalués (rachis lombaire, hanche totale, trochanter, col du fémur; tous les $\mathrm{P}<0,05)$. Les femmes séropositives à la TTG/EMA manifestaient également une prévalence beaucoup plus élevée d'ostéoporose $(67,7 \%$ par rapport à $44,8 \% ; \mathrm{P}<0,05)$. La densité osseuse était plus faible aux trois foyers de la hanche (tous les $\mathrm{P}<0,05$ ) chez les femmes séropositives à l'AGA, mais après avoir exclu les femmes séropositives à la TTG/EMA, la séropositivité isolée à l'AGA n'a révélé aucune association significative avec les mesures de densité osseuse. CONCLUSION : La séropositivité à la TTG/EMA s'associait à une densité osseuse plus faible et à une plus forte prévalence d'ostéoporose que chez les sujets témoins séronégatifs.
\end{abstract}

to the prevalence of osteoporosis in North American populations. A survey of patients (4) who were on a GFD for a mean of 7.5 years revealed a high prevalence of osteoporosis and low bone mass.

The most commonly used antibodies to screen for CD include immunoglobulin (Ig) A tissue transglutaminase (TTG), IgA endomysial (EMA) and antigliadin (AGA) (5). While there is some variation in performance characteristics, TTG and EMA have high reported specificities of $99 \%$ and $98 \%$, respectively, while AGA has a significantly lower specificity increased fracture risk (1). The etiology is multifactorial, with gut inflammation, calcium and vitamin D malabsorption, reduced calcium intake and secondary hyperparathyroidism being contributing factors (2). The studies examining bone mineral density (BMD) in CD (3) have been performed in different populations and include patients studied at diagnosis as well as patients who have been on a gluten-free diet (GFD) for a variable period of time. There are few studies pertaining 
(85\%) (6). The objective of the present study was to examine the role of CD seropositivity as a risk factor for decreased bone density in a clinical cohort of adult women who underwent BMD measurements that were performed up to six months before investigation for CD.

\section{METHODS}

The study protocol was approved by the Faculty of Medicine Research Ethics Board of the University of Manitoba (Winnipeg, Manitoba).

\section{Serological database}

In the province of Manitoba, all serological testing for CD is performed by a central immunology laboratory. From 1996 to 2007, all patients screened for CD had EMA and AGA serology testing performed, and from 2000 to 2007, TTG serology was also conducted.

EMA testing was performed according to the following protocol: serum samples were diluted and incubated with human umbilical cord substrate for $30 \mathrm{~min}$. Samples were then washed, incubated with fluorescein-conjugated guinea pig antihuman IgA for an additional $30 \mathrm{~min}$, washed again, then examined by fluorescence microscopy. Sera were considered positive if fluorescence was detected at dilutions of 1:5 or greater. AGA testing was performed using an ELISA-based test kit (EUROIMMUN, Germany), in which values of 20 relative units/mL or greater were considered positive. From 2000 to 2003, the guinea pig tissue transglutaminase assay was used (which has a lower reported sensitivity and specificity [7]) and, since 2003, TTG antibodies have been measured using an ELISA test kit (EUROIMMUN, Germany), with values considered positive if they exceeded 20 relative units $/ \mathrm{mL}$.

\section{BMD database}

The Manitoba BMD database contains all clinical BMD data for the province from 1990 to the present (more than 75,000 records) (8). This database has been carefully validated and extensively used for clinical research, with completeness and accuracy in excess of 99\% (9). Dual-energy x-ray absorptiometry scans were performed and analyzed in accordance with the manufacturer's (GE Lunar, USA) recommendations. Lumbar spine $\mathrm{T}$ scores (number of SDs above or below young adult mean BMD) and Z scores (number of SDs above or below agematched mean BMD) were calculated using the manufacturer's American Caucasian female reference values. Hip T scores and $\mathrm{Z}$ scores were calculated from the revised National Health and Nutrition Examination Survey (NHANES III) white female reference values (Prodigy version 8.8, USA) $(10,11)$. Vertebral BMD levels affected by artefact were excluded by experienced physicians using conventional criteria (12). Before 2000, dualenergy x-ray absorptiometry measurements were performed with a pencil-beam instrument (Lunar DPX, GE Lunar, USA), and after 2000, a fan-beam instrument was used (Lunar Prodigy, GE Lunar, USA). Instruments were cross-calibrated using anthropomorphic phantoms and 59 volunteers. No clinically significant differences were identified ( $\mathrm{T}$ score differences of less than 0.2). Therefore, all analyses were based on the unadjusted numerical results provided by the instrument. Densitometers showed stable long-term performance (coefficient of variation less than $0.5 \%$ ) and satisfactory in vivo precision (coefficient of variation 1.7\% for lumbar spine 1 to 4 , and $1.1 \%$ for the total hip) (13).

\section{Study population}

The Manitoba BMD database was linked to the provincial CD serology database to identify all women in Manitoba older than 20 years of age with BMD results preceding initial CD serology by six months or less. Patients with repeat CD serology were excluded from the analysis because these individuals often have a diagnosis of $\mathrm{CD}$ and serology is monitored to assess the effect of a GFD. Individuals undergoing baseline CD serology were unlikely to have been started on a GFD. For similar reasons, patients who underwent BMD testing performed after $\mathrm{CD}$ serology were excluded from the analysis to minimize any potential confounding effect of a GFD.

\section{Statistical analysis}

Univariate analyses were used to compare the two groups $\left(\chi^{2}\right.$ test for categorical data and Student's $t$ test for continuous data). Analysis of covariance (ANCOVA) was used to test for differences in the relationship between $\mathrm{T}$ scores at specific anatomical sites (lumbar spine, total hip, trochanter and femoral neck) and CD seropositivity. ANCOVA models were adjusted for age, height and weight. $\mathrm{P}<0.05$ was considered to be statistically significant. Statistical analyses were performed with Statistica version 8.0 (StatSoft Inc, USA).

\section{RESULTS}

TTG and EMA serology data were available for 376 women, 356 had AGA serology and 347 had both TTG/EMA and AGA serology. TTG/EMA seropositivity was identified in 31 women (8\%) and AGA seropositivity was identified in 71 women (20\%). The demographic and baseline characteristics of women who met the inclusion criteria are shown in Table 1. The mean duration between BMD assessment and serological testing was similar in all groups (3.1 months). The mean $( \pm S D)$ age was similar for AGA seronegative and seropositive patients ( $62.0 \pm 12.8$ years versus $62.2 \pm 12.4$ years, respectively). In the TTG/EMA seropositive group, mean age was slightly lower than for seronegative patients $(55.8 \pm 12.1$ years versus $62.8 \pm 12.4$ years; $\mathrm{P}<0.05)$ and height was slightly greater $(163.1 \pm 6.6 \mathrm{~cm}$ versus $160.0 \pm 6.9 \mathrm{~cm} ; \mathrm{P}<0.05)$, with no difference in weight or body mass index.

Table 1 also presents the unadjusted $T$ scores and age-adjusted $\mathrm{Z}$ scores for the different serogroups. Significantly lower mean Z scores were seen for all four sites in the TTG/EMA seropositive group $(\mathrm{P}<0.05)$. There was also a significantly larger number of osteoporotic women in the TTG/EMA seropositive group than in the seronegative control group (67.7\% versus $44.8 \%$, respectively; $\mathrm{P}<0.05)$. AGA seropositivity showed less consistent effects on bone density, with significantly lower mean $\mathrm{Z}$ scores of the total hip and femoral neck but no differences in the trochanter, lumbar spine or overall prevalence of osteoporosis.

Table 2 shows the least-squares mean (LSM) T scores according to CD serology after ANCOVA adjustment for age, weight and height. In the TTG/EMA seropositive group, there was a significantly lower mean $\mathrm{T}$ score at all sites than with seronegative patients, while in the AGA seropositive group, there was a significant reduction in $\mathrm{T}$ score at three of the four sites measured. 
TABLE 1

Patient demographics and baseline characteristics

\begin{tabular}{|c|c|c|c|c|}
\hline & \multicolumn{2}{|c|}{ TTG/EMA } & \multicolumn{2}{|c|}{ AGA } \\
\hline & Seronegative & Seropositive & Seronegative & Seropositive \\
\hline Patients, $\mathrm{n}$ & 345 & 31 & 285 & 71 \\
\hline Age, years & $62.8 \pm 12.4$ & $55.8 \pm 12.1^{*}$ & $62.0 \pm 12.8$ & $62.2 \pm 12.4$ \\
\hline Height, cm & $160.0 \pm 6.9$ & $163.1 \pm 6.6^{*}$ & $160.1 \pm 6.9$ & $160.8 \pm 7.2$ \\
\hline Body mass index, $\mathrm{kg} / \mathrm{m}^{2}$ & $25.5 \pm 5.3$ & $24.5 \pm 6.2$ & $25.6 \pm 5.5$ & $25.1 \pm 5.3$ \\
\hline Total hip T score & $-1.35 \pm 1.34$ & $-1.79 \pm 1.15$ & $-1.29 \pm 1.4$ & $-1.69 \pm 1.04^{*}$ \\
\hline Total hip Z score & $-0.29 \pm 1.27$ & $-1.05 \pm 1.13^{*}$ & $-0.27 \pm 1.32$ & $-0.64 \pm 1.06^{*}$ \\
\hline Femoral neck T score & $-1.68 \pm 1.07$ & $-1.86 \pm 0.82$ & $-1.63 \pm 1.12$ & $-1.90 \pm 0.83^{*}$ \\
\hline Femoral neck Z score & $-0.26 \pm 1.08$ & $-0.74 \pm 0.83^{\star}$ & $-0.24 \pm 1.13$ & $-0.49 \pm 0.86^{*}$ \\
\hline Trochanter T score & $-1.63 \pm 1.31$ & $-2.18 \pm 1.21^{\star}$ & $-1.58 \pm 1.35$ & $-2.00 \pm 1.08$ \\
\hline
\end{tabular}

Data are presented as mean $\pm S D$ unless indicated otherwise. ${ }^{*} P<0.05$, seronegative versus seropositive. AGA Antigliadin antibody; BMD Bone mineral density; EMA Immunoglobulin A endomysial antibody; TTG Tissue transglutaminase antibody

TABLE 2

Adjusted bone mineral density T scores for TTG/EMA and AGA seronegative and seropositive groups

\begin{tabular}{|c|c|c|c|c|}
\hline & \multicolumn{2}{|c|}{ TTG/EMA } & \multicolumn{2}{|c|}{ AGA } \\
\hline & Seronegative & Seropositive & Seronegative & Seropositive \\
\hline Total hip & $-1.34 \pm 0.06$ & $-1.92 \pm 0.20$ & $-1.30 \pm 0.06$ & $-1.65 \pm 0.13$ \\
\hline Lumbar 1-4 & $-1.96 \pm 0.07$ & $-2.59 \pm 0.24$ & $-1.93 \pm 0.09$ & $-2.25 \pm 0.17$ \\
\hline Femoral neck & $-1.66 \pm 0.05$ & $-2.03 \pm 0.16$ & $-1.63 \pm 0.05$ & $-1.88 \pm 0.10$ \\
\hline Trochanter & $-1.62 \pm 0.06$ & $-2.29 \pm 0.19$ & $-1.59 \pm 0.06$ & $-1.97 \pm 0.13$ \\
\hline
\end{tabular}

Data are presented as least-squares mean \pm SE from analysis of covariance models (age, height and weight adjusted). AGA Antigliadin antibody; EMA Immunoglobulin A endomysial antibody; TTG Tissue transglutaminase antibody

Figure 1 compares the ANCOVA-adjusted T score LSM in antibody-discordant individuals. Patients were divided into three mutually exclusive groups: TTG or EMA seropositive $(n=29)$, AGA seropositive only ( $\mathrm{n}=50$, TTG and EMA seronegative), and controls seronegative for TTG, EMA and AGA $(n=268)$. Compared with seronegative women, T score LSMs were significantly lower at all sites in the TTG/EMA seropositive women $(\mathrm{P}<0.05)$, while isolated AGA seropositivity had T score LSMs indistinguishable from controls. For the lumbar spine, total hip and trochanter, there was a significant difference $(\mathrm{P}<0.05)$ between the TTG/EMA seropositive individuals compared with isolated AGA seropositive women, with a nonsignificant trend toward a difference in the femoral neck $(\mathrm{P}=0.15)$.

\section{DISCUSSION}

The present study determined that adult women who were seropositve for EMA and/or TTG had lower bone density at all measured sites than the seronegative control group. All patients had their bone density measurements taken before antibody testing for $\mathrm{CD}$, essentially eliminating any possible confounding effect of a GFD on bone density results. Although Meyer et al (4) did not find any difference between treated and untreated patients, other studies have demonstrated a modest improvement in the bone density of subjects who were on a GFD (14).
We found a significantly greater prevalence of osteoporosis as defined by a $T$ score of -2.5 or lower $(67.7 \%$ for seropositive versus $44.8 \%$ for seronegative subjects). The only other North American study of bone density in CD, a cross-sectional study from the United States (4) including 31 newly diagnosed patients and 97 treated adult men and women, found a high prevalence of osteopenia or osteoporosis in the lumbar spine $(72 \%)$ and femoral neck (71\%). In a study of 86 consecutive newly diagnosed Italian subjects with CD (15), there was a $40 \%$ prevalence of lumbar osteopenia and a $26 \%$ prevalence of osteoporosis. In a smaller study of 25 newly diagnosed patients from Argentina (16), there was a $72 \%$ prevalence of lumbar osteopenia ( $\mathrm{T}$ score of less than -1.0$)$. The World Health Organization criteria for osteoporosis ( $\mathrm{T}$ score of -2.5 or lower) were not given in this study. Similar results have been reported in adults with newly diagnosed CD in various European countries (17-25).

The relatively high prevalence of osteoporotic bone density $\mathrm{T}$ scores in our study warrants comment. There is likely to be an element of clinical referral ('channelling') bias, for which patients undergo subsequent celiac serological testing. In the present study, the indication for ordering celiac serology testing was unknown. It is important to note that none of these women had celiac serology before bone density testing, which removes this as a source of bias contributing to differences between 


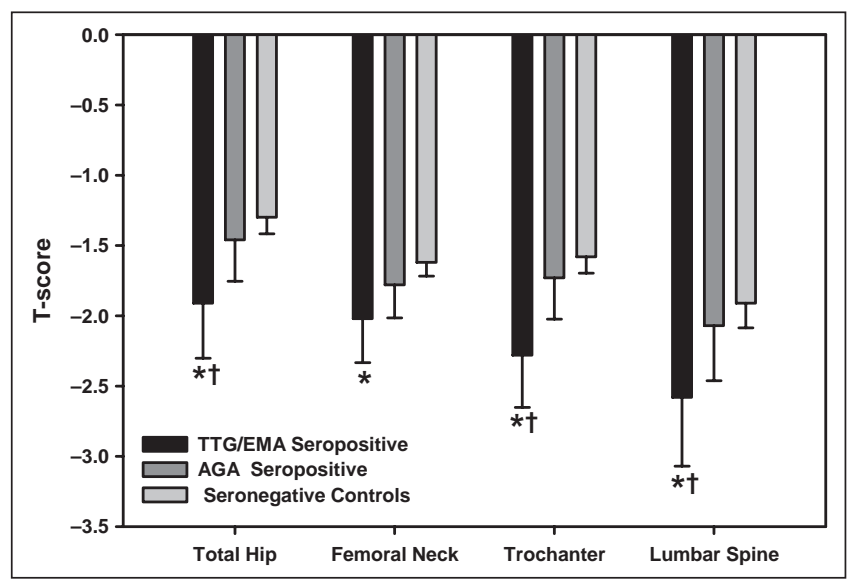

Figure 1) $T$ scores for tissue transglutaminase (TTG)/immunoglobulin A endomysial antibody (EMA) seropositivity and isolated antigliadin antibody (AGA) seropositivity. Data are presented as least-squares means with 95\% CIs from analysis of covariance models (age, height and weight adjusted). $* P<0.05$ versus seronegative controls; ${ }^{\dagger} \mathrm{P}<0.05$ versus $\mathrm{AGA}$ seropositivity

the seropositive and seronegative women. In our study, the lowest BMD T scores were found in the lumbar spine in both seronegative and seropositive patients, and the absolute difference between TTG/EMA seropositive women and seronegative controls was greatest for the lumbar spine and trochanter. These sites are rich in trabecular bone, which may show earlier changes than predominantly cortical sites, particularly in relatively young women (mean age 62.2 years). In a study of North American adult women, Meyer et al (4) found similar rates of osteoporosis in the radius, femoral neck and spine. Although biopsy information was not available to confirm the diagnosis of CD in our study, previous work (6) has demonstrated very high sensitivity (greater than 98\%) and specificity (greater than $98 \%$ ) of TTG and EMA antibodies for the diagnosis of CD. Therefore, it is likely that our results are also applicable to patients with biopsy-proven $\mathrm{CD}$, and supports the association between $\mathrm{CD}$ and decreased bone density.

While AGA was one of the earliest serological markers available for the diagnosis of $\mathrm{CD}$, it is less sensitive and specific (26). The laboratory performing serological testing for CD in Manitoba has been conducting this assay in addition to the EMA and TTG antibody tests. As would have been predicted, AGA positivity (with lower likelihood of true CD) showed a weaker association with decreased bone density. Because of the lower specificity of AGA, it is probable that many individuals had false-positive results and, in fact, did not have CD.

Finally, although it is recommended that patients who test positive for EMA or TTG be biopsied to confirm the diagnosis $(6,27)$, this practice is frequently not adhered to and patients may be started on a GFD based solely on serological results. In a Canadian study (28), 44 of 284 (15\%) EMA-positive patients started a GFD without undergoing a small bowel biopsy, either because their primary physician empirically started them on a GFD or they refused a biopsy. Our results show that positive TTG and EMA are associated with low bone density and, thus, patients who do not have their diagnosis confirmed with biopsy should still have their bone density assessed.

\section{CONCLUSION}

The present study examined bone density in adult women in the six months before serological testing for CD. Positive TTG/EMA serology was associated with a significant reduction in bone density, which affected the spine, total hip, trochanter and femoral neck. Patients who are seropositive for TTG/EMA antibodies should be assessed for osteoporosis and fracture risk regardless of whether a confirmatory duodenal biopsy has been performed.

ACKNOWLEDGEMENTS: The present article has been reviewed and approved by the members of the Manitoba Bone Density Program Committee.

\section{REFERENCES}

1. Hopper AD, Hadjivassiliou M, Butt S, Sanders DS. Adult coeliac disease. BMJ 2007;335:558-62.

2. Tilg H, Moschen AR, Kaser A, Pines A, Dotan I. Gut inflammation and osteoporosis: Basic and clinical concepts. Gut 2008;57:684-94.

3. Bianchi ML, Bardella MT. Bone in celiac disease. Osteoporos Int 2008;12:1705-16

4. Meyer D, Stavropolous S, Diamond B, Shane E, Green PH. Osteoporosis in a North American adult population with celiac disease. Am J Gastroenterol 2001;96:112-9.

5. Green PH, Cellier C. Celiac disease. N Engl J Med 2007;357:1731-43

6. Rostom A, Murray JA, Kagnoff MF. American Gastroenterological Association (AGA) Institute technical review on the diagnosis and management of celiac disease. Gastroenterology 2006;131:1981-2002.

7. Wong RC, Wilson RJ, Steele RH, Radford-Smith G, Adelstein S. A comparison of 13 guinea pig and human anti-tissue transglutaminase antibody ELISA kits. J Clin Pathol 2002;55:488-94.

8. Leslie WD, Metge C. Establishing a regional bone density program: Lessons from the Manitoba experience. J Clin Densitom 2003;6:275-82.

9. Leslie WD, Caetano PA, MacWilliam LR, Finlayson GS Construction and validation of a population-based bone densitometry database. J Clin Densitom 2005;8:25-30.

10. Binkley N, Kiebzak GM, Lewiecki EM, et al. Recalculation of the NHANES Database SD improves T-score agreement and reduces osteoporosis prevalence. J Bone Miner Res 2005;20:195-201.

11. Kanis JA, McCloskey EV, Johansson H, Oden A, Melton LJ III, Khaltaev N. A reference standard for the description of osteoporosis. Bone 2008;42:467-75.

12. Hansen KE, Binkley N, Christian R, et al. Interobserver reproducibility of criteria for vertebral body exclusion. J Bone Miner Res 2005;20:501-8.

13. Leslie WD. The importance of spectrum bias on bone density monitoring in clinical practice. Bone 2006;39:361-8.

14. Bernstein CN, Leslie WD, Leboff MS. AGA technical review on osteoporosis in gastrointestinal diseases. Gastroenterology 2003;124:795-841.

15. Sategna-Guidetti C, Grosso SB, Grosso S, et al. The effects of 1 -year gluten withdrawal on bone mass, bone metabolism and nutritional status in newly-diagnosed adult coeliac disease patients. Aliment Pharmacol Ther 2000;14:35-43.

16. Bai JC, Gonzalez D, Mautalen C, et al. Long-term effect of gluten restriction on bone mineral density of patients with coeliac disease. Aliment Pharmacol Ther 1997;11:157-64.

17. McFarlane XA, Bhalla AK, Robertson DA. Effect of a gluten-free diet on osteopenia in adults with newly diagnosed coeliac disease. Gut 1996;39:180-4.

18. Valdimarsson T, Lofman O, Toss G, Strom M. Reversal of osteopenia with diet in adult coeliac disease. Gut 1996;38:322-7.

19. Corazza GR, Di SA, Cecchetti L, et al. Bone mass and metabolism in patients with celiac disease. Gastroenterology 1995;109:122-8.

20. Ciacci C, Maurelli L, Klain M, et al. Effects of dietary treatment on bone mineral density in adults with celiac disease: Factors predicting response. Am J Gastroenterol 1997;92:992-6.

21. Mustalahti K, Collin P, Sievanen H, Salmi J, Maki M. Osteopenia in patients with clinically silent coeliac disease warrants screening. Lancet 1999;354:744-5. 
22. Walters JR, Banks LM, Butcher GP, Fowler CR. Detection of low bone mineral density by dual-energy $\mathrm{x}$-ray absorptiometry in unsuspected suboptimally treated coeliac disease. Gut 1995;37:220-4

23. Keaveny AP, Freaney R, McKenna MJ, Masterson J, O'Donoghue DP. Bone remodeling indices and secondary hyperparathyroidism in celiac disease. Am J Gastroenterol 1996;91:1226-31.

24. Kemppainen T, Kroger H, Janatuinen E, et al. Bone recovery after a gluten-free diet: A 5-year follow-up study. Bone 1999;25:355-60.

25. Kemppainen T, Kroger H, Janatuinen E, et al. Osteoporosis in adult patients with celiac disease. Bone 1999;24:249-55.
26. Rostom A, Dube C, Cranney A, et al. The diagnostic accuracy of serologic tests for celiac disease: A systematic review. Gastroenterology 2005;128:S38-S46.

27. Hill ID, Dirks MH, Liptak GS, et al. Guideline for the diagnosis and treatment of celiac disease in children: Recommendations of the North American Society for Pediatric Gastroenterology, Hepatology and Nutrition. J Pediatr Gastroenterol Nutr 2005;40:1-19.

28. McGowan KE, Lyon ME, Loken SD, Butzner JD. Celiac disease: Are endomysial antibody test results being used appropriately? Clin Chem 2007;53:1775-81. 


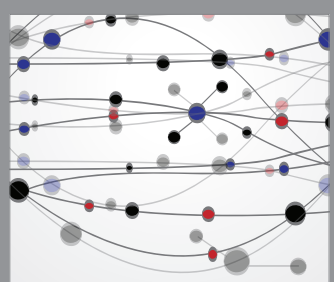

The Scientific World Journal
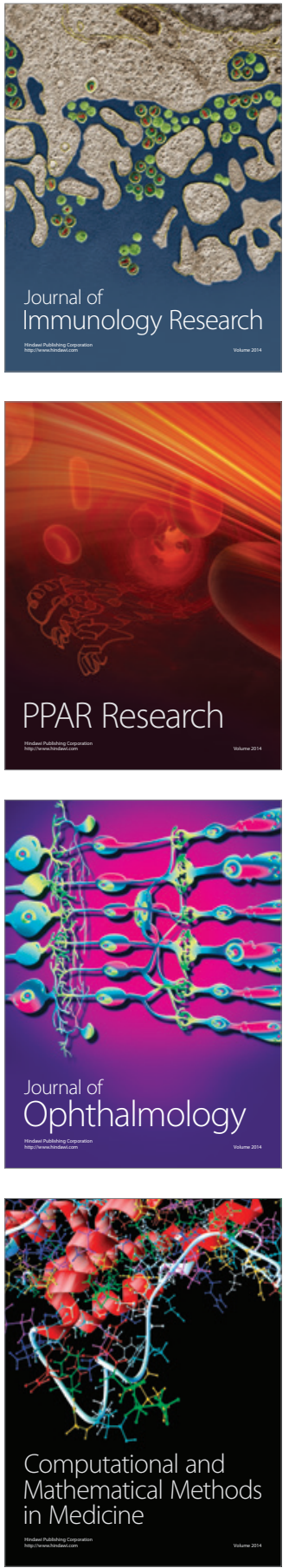

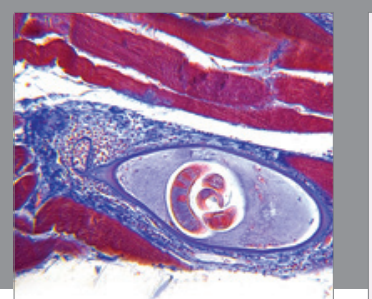

Gastroenterology Research and Practice

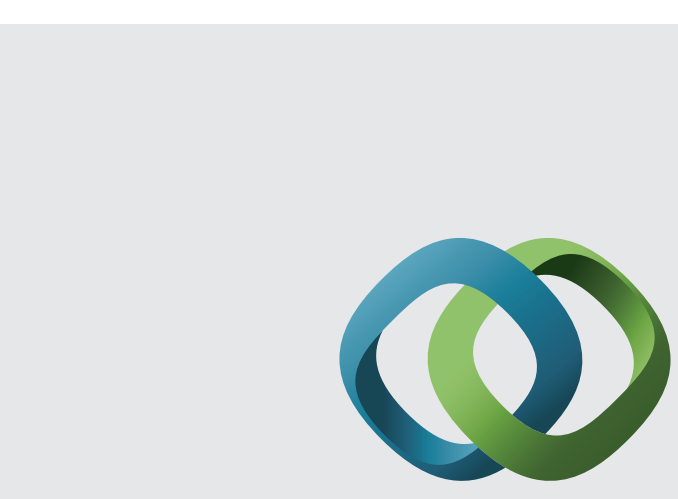

\section{Hindawi}

Submit your manuscripts at

http://www.hindawi.com
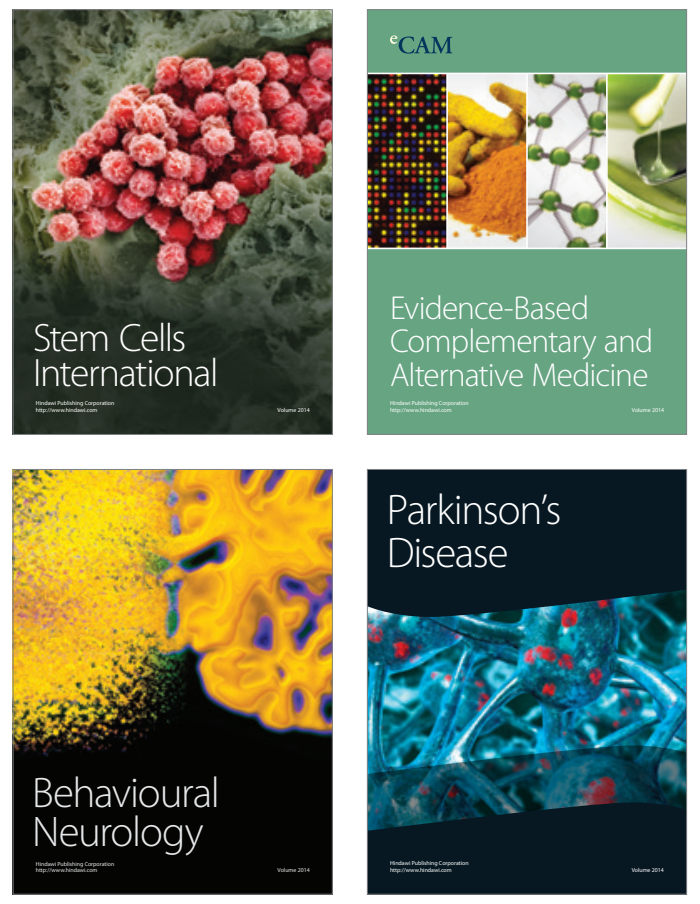
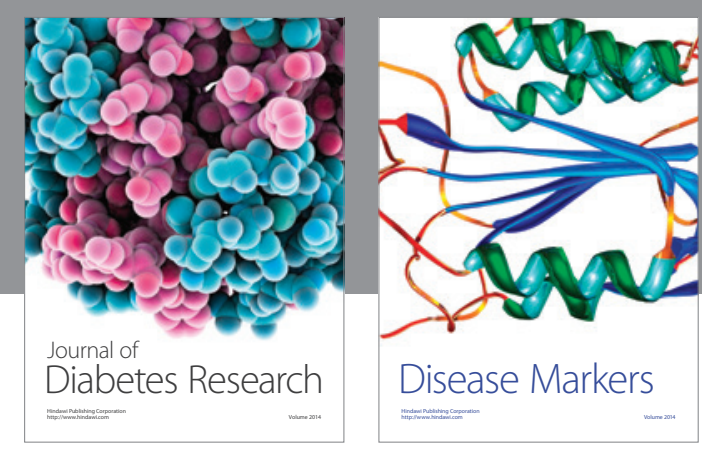

Disease Markers
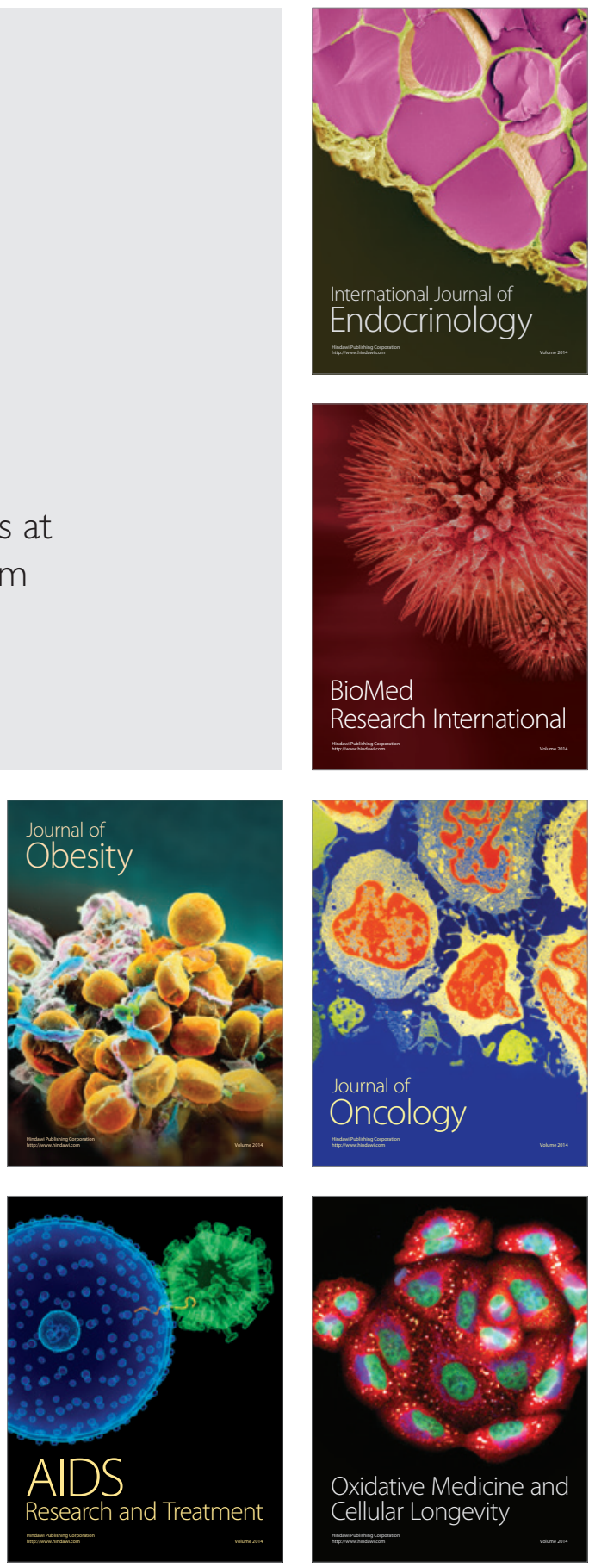